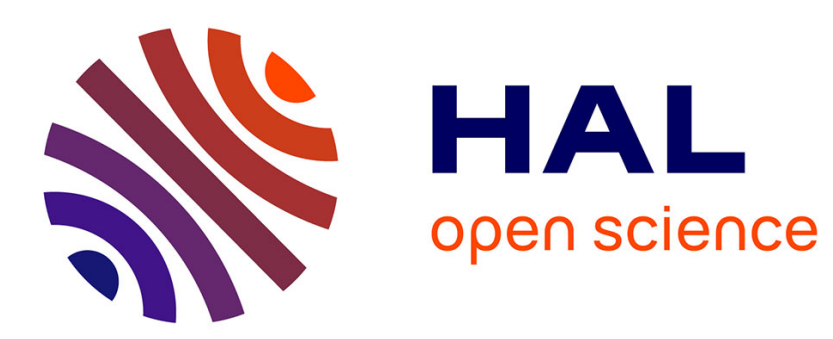

\title{
Do Dollar Forecasters Believe too Much in PPP?
}

Lukas Menkhoff, Rafael Rebitzky, Michael Schröder

\section{To cite this version:}

Lukas Menkhoff, Rafael Rebitzky, Michael Schröder. Do Dollar Forecasters Believe too Much in PPP?. Applied Economics, 2008, 40 (03), pp.261-270. 10.1080/00036840500428153 . hal-00581988

\section{HAL Id: hal-00581988 \\ https://hal.science/hal-00581988}

Submitted on 1 Apr 2011

HAL is a multi-disciplinary open access archive for the deposit and dissemination of scientific research documents, whether they are published or not. The documents may come from teaching and research institutions in France or abroad, or from public or private research centers.
L'archive ouverte pluridisciplinaire HAL, est destinée au dépôt et à la diffusion de documents scientifiques de niveau recherche, publiés ou non, émanant des établissements d'enseignement et de recherche français ou étrangers, des laboratoires publics ou privés. 


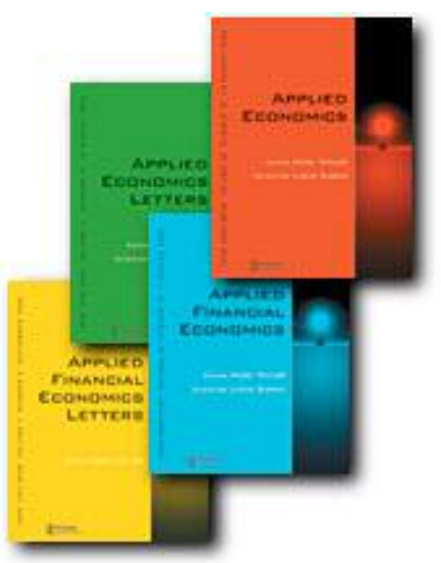

Do Dollar Forecasters Believe too Much in PPP?

\begin{tabular}{|c|c|}
\hline Journal: & Applied Economics \\
\hline Manuscript ID: & APE-05-0500 \\
\hline Journal Selection: & Applied Economics \\
\hline $\begin{array}{r}\text { Date Submitted by the } \\
\text { Author: }\end{array}$ & 13-Sep-2005 \\
\hline JEL Code: & $\begin{array}{l}\text { F31 - Foreign Exchange < F3 - International Finance < F - } \\
\text { International Economics, G14 - Information and Market } \\
\text { Efficiency|Event Studies }<\text { G1 - General Financial Markets }<\text { G - } \\
\text { Financial Economics }\end{array}$ \\
\hline Keywords: & $\begin{array}{l}\text { exchange rate expectations, forecasting, fundamental analysis, } \\
\text { technical analysis, purchasing power parity }\end{array}$ \\
\hline
\end{tabular}

powered by ScholarOne

Manuscript Central ${ }^{\text {TH}}$ 


\title{
Do Dollar Forecasters Believe too Much in PPP?
}

\author{
Lukas Menkhoff, University of Hannover, Germany \\ Rafael Rebitzky, University of Hannover, Germany \\ Michael Schröder, Centre for European Economic Research, Mannheim, Germany
}

\begin{abstract}
:
This paper extends earlier studies on exchange rate expectations' formation by using new data and adding information about forecasters' reliance on fundamental analysis for the first time. We replicate the conventional result of non rational expectations. Moreover, biases in expectations are identified as professionals significantly belief too much in mean reversion, mean being represented by PPP. When respondents are grouped on their reliance to fundamental analysis, fundamentalists reveal an even stronger bias. Those, who rely the least on fundamentals - preferring technical analysis instead -, show a significantly smaller bias towards PPP in lieu of expecting too much trend extrapolation. Biased beliefs will grow stronger when the US Dollar is further away from PPP. Finally, the accuracy of the expectations is poor for both groups however we find directional forecasting ability.
\end{abstract}

JEL-Classification: F31 (foreign exchange), G14 (information)

Keywords: $\quad$ Exchange rate expectations, forecasting, fundamental analysis, technical analysis, purchasing power parity

September 13, 2005

Corresponding: Lukas Menkhoff, Department of Economics, University of Hannover, Königsworther Platz 1, D-30167 Hannover, Germany, menkhoff@ gif.uni-hannover.de 


\title{
Do Dollar Forecasters Believe too Much in PPP?
}

\begin{abstract}
:
This paper extends earlier studies on exchange rate expectations' formation by using new data and adding information about forecasters' reliance on fundamental analysis for the first time. We replicate the conventional result of non rational expectations. Moreover, biases in expectations are identified as professionals significantly belief too much in mean reversion, mean being represented by PPP. When respondents are grouped on their reliance to fundamental analysis, fundamentalists reveal an even stronger bias. Those, who rely the least on fundamentals - preferring technical analysis instead -, show a significantly smaller bias towards PPP in lieu of expecting too much trend extrapolation. Biased beliefs will grow stronger when the US Dollar is further away from PPP. Finally, the accuracy of the expectations is poor for both groups however we find directional forecasting ability.
\end{abstract}

JEL-Classification: F31 (foreign exchange), G14 (information)

Keywords: $\quad$ Exchange rate expectations, forecasting, fundamental analysis, technical analysis, purchasing power parity

September 13, 2005 


\section{Do Dollar Forecasters Believe too Much in PPP?}

\section{Introduction}

Since about 20 years we know that exchange rate forecasts of professionals show some degree of "irrationality" (Dominguez, 1986, p.281). It has become a stylized fact that these forecasts do not hold predictive power and that forecasters do not even use the entire information available (surveys by Takagi, 1991, Sarno and Taylor, 2002). Too little is known about possible sources of this pattern. Our research contributes towards a better understanding of this seemingly "irrational" behavior by using a new database. This enables us to analyze monthly US-Dollar/Euro and USDollar/Deutsche Mark forecasts for more than 12 years, i.e. significantly longer than earlier studies. Additionally and for the first time on this literature, the forecasts of professionals are examined in groups defined by their relative reliance on fundamental analysis. We determine that forecasters in general rely too much on mean reversion on exchange rates, mean represented by purchasing power parity (PPP). The revealing fact is that fundamentalists show even more biased forecasts - this is consistent to the opinion that Dollar forecasters believe too much in PPP.

Right from its beginning the thorough analysis of exchange rate expectations have been motivated under the issue of market efficiency. The Frankel and Froot (1987a) "finding of systematic expectational errors" (p.150) set the ball to roll and was confirmed by numerous authors and various samples (see MacDonald, 2000). The many repetitions of the early results might have been responsible for the fact that a caveat has been readily neglected so far: Frankel and Froot (1987a) reveal systematic errors but they also report that the sign of the error may depend on the sample period. This puts into question, whether deeper forces at work appear that may play a responsible part upon the changing sign. An analysis of this issue requires longer time series exceeding the often used two to four years.

Another important issue already addressed by Frankel and Froot (1990) is the forecast heterogeneity. Earlier studies, such as Dominguez (1986) or Frankel and Froot (1987a, 1987b), are based on consensus forecasts. More recent studies though analyze individual expectation data to reveal indeed different pattern in forecasts (e.g. Bénassy-Quéré et al., 2003). This line of work describes and examines heterogeneity but does not allow inferences on possible sources of heterogeneity. 
For the latter purpose one would need additional, exogenous information (see, Moosa and Shamsuddin, 2004, p. 1606). A rare example is shown in the analysis of the exchange rate forecasts of commercial services (Goodman, 1979), where technically-oriented services perform better than economics-oriented services. However, the data spans less than three years and considers only 13 forecasting services. Another example is the examination of a relatively short Japanese sample which allows classification of six groups, such as exporters etc. This data indicates that expectations can be affected by private information (Wakita, 1989) but is also influenced by wishful thinking (Ito, 1990). It is again Frankel and Froot (1990) who suggest another cut in the data that might be warranted: they speculate that there may be forecasters "who think long-term" and consequently form regressive expectations then again others "who think short-term" form rather static expectations. We know that professionals picture expectations differently, though we need a rationale for this behavior such as the one suggested by Frankel and Froot - provided that we want to reach beyond description and build an economic understanding instead.

We read the suggestion of long-term motivated regressive exchange rate expectations as a hint towards the possible importance of PPP. PPP is a core part in many exchange rate models, it is an intuitively plausible benchmark for thinking about exchange rates and - most important - it has received credit as an empirically valid concept as surveyed by Rogoff (1996) or Taylor and Taylor (2004). To pinpoint it further: as there is no single exchange rate theory that holds empirically (Frankel and Rose, 1995, Sarno and Taylor, 2002), which economic concept forecasters ought to be used if not PPP?

An examination of this issue would therefore profit from data that fulfils two conditions: the time series should be long and there should be information indicating that the economic concept of PPP drives expectations. The long period is needed in order to cover exchange rate movements to and from PPP. Additional information towards motivation of forecasters is useful to derive directly the importance of PPP. To the best of our knowledge, there is no data set in the literature that would fulfil these two conditions except for the data used here.

We show that professionals from Germany, covering more than the past 12 years, behave very conventionally: our first result shows that according to standard surveys their expectations are not purely rational and they seem to apply different kinds of expectation formation. As this is in unison to the literature, we declare it as 
indication that other results derived from our data can be generalized too. Second, biases in expectations are identified in the consensus forecasts, as professionals significantly belief too much in mean reversion, mean being represented by PPP. Third, according to their reliance on fundamental analysis and as soon as the sample is divided into three groups, the forecasters who rely most strongly on fundamentals analysis - "fundamentalists" - reveal an even stronger bias. The group who relies the least on fundamentals - prefer technical analysis instead: "technicians" - shows a much smaller bias. So, stronger belief in fundamentals and thus PPP is revealed as a source of bad forecasting performance. Fourth, though, the technicians' "advantage" in this respect is compensated by another bias not unexpected for technicians, showing too much expectation of trend extrapolation. Fifth, we illustrate, that forecasting biases of fundamentalists and technicians will get stronger when the exchange rate is further away from PPP. Finally, 'point forecasts' performance of both groups is of similar poor quality. Interestingly, all groups distinguished show some directional forecasting ability.

The remainder is structured as follows. Section 2 describes data, whereas results are presented in Section 3. Section 4 concludes.

\section{Data}

Our expectation data is based upon the ZEW Financial Market Survey. The Centre for European Economic Research (ZEW) of Mannheim (Germany) collects every month numerous economic and financial forecasts with a horizon of six months. The ZEW survey is a qualitative questionnaire, which has been driven since December 1991 and soon grew up to a stable panel with more than 300 participants in Germany. Around 75 per cent of the participants work in the banking sector (as analysts, fund managers etc.) and 25 per cent work either in the insurance or in the industrial sector. ${ }^{1}$ In comparison to other surveys the amount of participants is relative large and its composition according to their profession is similar to others (Consensus forecasts, London, contain 75 per cent participants from financial institutions). The forecasts collected are standardized by fax and are usually processed on the last Friday of each month.

\footnotetext{
${ }^{1}$ The ZEW publishes out of the ZEW Financial Market Survey regularly amongst others the ZEW Indicator of Economic Sentiment, which is a leading indicator for the German economy and of similar prominence like the ifo Index.
} 
Our dataset contains the individual six months exchange rate forecasts of the US-Dollar/Euro (respectively the US-Dollar/Deutsche Mark) from December 1991 to April 2004 and sums up to a total of 149 surveys. To our knowledge no other study uses a panel of monthly exchange rate expectations with a dataset as long as ours. ${ }^{2}$ Additionally we use daily US-Dollar/Euro and US-Dollar/Deutsche Mark rates from the Deutsche Bundesbank, six month Libor rates from EcoWin and price index data from the International Financial Statistics (IFS) of the International Monetary Fund (IMF).

We are aware about criticism regarding the use of survey data for modelling expectations in general and for financial forecasts in particular. Nevertheless, incentives for participants not to reveal their true beliefs are very limited as the ZEW publishes the aggregated forecasts (consensus forecasts) only. Moreover manipulating the data with extreme forecasts is practically impossible, due to around 300 participants and the qualitative responses given. Additionally the incentive to participate at the survey in order to get an extensive summary of the consensus data with additional background information from the ZEW directly seems to be quite strong as this data is well covered by the financial media.

To get a first impression of the exchange rate forecasts, some descriptive statistics are presented in Table 1. For comparison we include the corresponding six month forward rates and the realized exchange rates at the same time. With respect to the level statistics one recognizes that consensus forecasts as well as forward rates behave similar to realized exchange rates though forward rates resemble exchange rates even better. If one looks at the change statistics, consensus forecasts still behave similar to realized exchange rates, in contrary to forward rates which differ especially on their variability measures. Finally the consensus expects a slightly stronger US-Dollar on average towards the Euro whereas the US-Dollar actually weakens on average.

Additionally in a specific survey ZEW participants were asked on which information they actually base their exchange rate forecasts (see ZEW Financial Market Report, 2004). ${ }^{3}$ This enables us to categorize the participants according to their use of

\footnotetext{
${ }^{2}$ Recently Stadtmann (2004) uses the Wall Street Journal survey which covers a longer time period (1989 - 2003), but at the cost of semi yearly data only, which generates just 30 data points.

${ }^{3}$ Participants were asked to distribute 100 points amongst the categories fundamental, technical and flow analysis according to the way how they do their exchange rate analysis.
} 
analytical instruments. We base our classification on the use of fundamental analysis and organize the survey participants in fundamentalists, technicians and intermediates. We could not find any significant difference between people who use primarily technical analysis or flow analysis due to the fact, that flow analysis is used to a much smaller degree than other instruments of analysis (the average share of flow analysis in the forecasting process sums up to 10 per cent, whereas technical analysis adds up to 30 per cent and fundamental analysis to 60 per cent). ${ }^{4}$ The respective outcome of this questionnaire is summarized in Table 2. One can see that the group of fundamentalists is about as big as the group of technicians, due to the threshold values being chosen. The average numbers of these two groups representing more than 35 seem big enough for our analysis. ${ }^{5}$

\section{Results}

In the following regression analysis we use OLS estimators corrected for Newey-West standard-errors (see, Newey and West, 1987). We choose five lags as a result of the overlapping problem attributed to monthly forecasts with a six month forecast horizon, which imparts a fifth order moving average error process (see, for example Hansen and Hodrick, 1980). In addition and owing to the qualitative nature of the expectation data we use the quantification technique from Carlson and Parkin (1975) to generate point forecasts. ${ }^{6}$ Due to non-stationarity characteristics of the time series, we use change forecasts rather than point forecasts. Detailed descriptions of the calculations and analyzed variables are given in each of the attached tables.

\subsection{Rationality of expectations}

In order to check characteristics of our survey participants with well established results in the literature, we perform conventional tests of forecast rationality. Since

\footnotetext{
${ }^{4}$ This could be connected to the panel composition, i.e. analysts being more represented than traders. We know that traders rely significantly more than others on flow analysis (see Gehrig and Menkhoff, 2005). The high representation of technical analysis seems very plausible, however, as it is known that fund managers - which are represented here too - heavily rely on technical investment strategies, such as momentum trading (Menkhoff and Schmidt, 2005).

${ }^{5}$ This average number of responses reflects the fact that we include only those observations in the sample where the person responding to the "use of information-question" does not change during time. Therefore, it seems almost unavoidable that the sample becomes smaller the more we go back into history.

${ }^{6}$ Taylor (1989), among others, also uses this method to quantify categorical responses.
} 
Dominguez (1986) and for this purpose primarily it is common to check the degree of unbiasedness as well as efficiency.

Test of unbiasedness:

$$
\begin{aligned}
& \Delta s_{t+6}=\alpha+\beta \cdot \Delta s_{t+6}^{e} \\
& \Delta s_{t+6}^{e}-\Delta s_{t+6}=\alpha+\beta \cdot F D_{t+6}
\end{aligned}
$$

The unbiasedness test is modelled in equation (1), where the change of the exchange rate $\left(\Delta \mathrm{s}_{\mathrm{t}+6}\right)$ is regressed on the corresponding expectation change $\left(\Delta \mathrm{s}_{\mathrm{t}+6}^{\mathrm{e}}\right)$. To satisfy the postulate of rationality, the estimated value of $\beta$ has to be one, whereas $\alpha$ needs to be zero. Additionally in equation (2) the difference of the expected exchange rate change and the actual change is regressed on the six months forward rate premium $\left(F D_{t+6}\right)$. To confirm efficiency and rationality of the expectations, it is required that $\beta$ as well as $\alpha$ are both zero.

Table 3 presents results on the test of unbiasedness which reject the hypothesis of rational expectations, because $\beta$ is significantly below unity. Furthermore the test of orthogonality shows evidence of irrationality too, since $\beta$ is significantly above null which implies that even data easily available such as the forward premium is not completely processed in exchange rate forecasts. ${ }^{7}$ All in all, the unbiased expectations hypothesis (and therefore the assumption of rationality) on consensus forecasts has to be rejected, being well in-line with the literature (e.g. Kim, 1997, MacDonald, 2000).

\subsection{Bias of expectations}

However, our primary interest lies on the sources for the irrationality of FXforecasts. To reveal the kind of forecast pattern we estimate a hybrid model. Since the work by Frankel and Froot (1987a) a lot of analyses have been carried out to estimate the expectation formation for exchange rates, i.e. extrapolative, adaptive, regressive expectations and some sort of mixed models on former (see e.g. Cavaglia et al., 1993, Ito, 1994, Bénassy-Quéré et al., 2003). Summarizing it figures out that depending on the forecast horizon, short-term forecasts exhibit evidence of destabilizing behavior whereas long-term forecasts show stabilizing evidence.

\footnotetext{
${ }^{7}$ Not surprisingly, running the unbiasedness test for the forward rate reveals strongly biased results as well.
} 
Here we use a mixed model to regress the exchange rate forecasts on an extrapolative and a regressive term, since the former term covers well technical orientated forecaster behavior, whereas a regressive term should display the way how fundamentalists form their expectations. Furthermore, this procedure fits well into the relevant literature for comparative purposes (e.g. Moosa and Shamsuddin, 2004).

Expectations formation:

Systematic bias:

$$
\begin{aligned}
& \Delta s_{t+6}^{e}=\alpha+\gamma \cdot\left(s_{t}-s_{t-1}\right)+v \cdot\left(\overline{s_{t}}-s_{t}\right) \\
& \Delta s_{t+6}^{e}-\Delta s_{t+6}=\alpha+\gamma \cdot\left(s_{t}-s_{t-1}\right)+v \cdot\left(\bar{s}_{t}-s_{t}\right)
\end{aligned}
$$

Equation (3) shows the expectation mechanism. The expected change of the exchange rate is regressed on an extrapolative term $\left(s_{t}-s_{t-1}\right)$, which contains the previous one month change of the exchange rate. The second term on the right side of the equation displays the regressive formation $\left(\bar{s}_{\mathrm{t}}-s_{\mathrm{t}}\right)$. The latter one is based upon the difference between a fundamental equilibrium and the current exchange rate. To generate the fundamental variable we have chosen the well known relative PPP model and calculated corresponding rates upon PPI differences. In addition to that we would like to find out, whether the consensus relies too much on these expectations concepts on average. Doing so, we use again the expectation errors (see notes to equation 2) and follow the approach of Frankel and Froot (1987a, pp. 147150 ) in equation (4), regressing them on the expectations mechanisms.

The results in Table 4 show that the consensus is based upon a mixture of extrapolative and regressive expectation, so both mechanisms seem to matter. More interestingly the results for equation (4) show that forecasters rely too much on regressive expectations on average, whereas the same doesn't hold in respect to the extrapolation of current trends. We can summarize that the participants of the ZEW panel rely too heavily on the concept of PPP when forming US-Dollar/Euro forecasts in some way.

\subsection{Expectations of fundamentalists and technicians}

In this section we run the same regressions for the separated groups as in section 3.2. We would like to know, whether there are any differences in the way that groups form exchange rate expectations (indicator ${ }^{i}$ separates the different groups). 
$\begin{array}{ll}\text { Expectations formation: } & \Delta s_{t+6}^{e, i}=\alpha^{i}+\gamma^{i} \cdot\left(s_{t}-s_{t-1}\right)+v^{i} \cdot\left(\bar{s}_{t}-s_{t}\right) \\ \text { Systematic bias: } & \Delta s_{t+6}^{e, i}-\Delta s_{t+6}=\alpha^{i}+\gamma^{i} \cdot\left(s_{t}-s_{t-1}\right)+v^{i} \cdot\left(\bar{s}_{t}-s_{t}\right)\end{array}$

Table 5 shows that the $\gamma^{i}$ coefficient of equation (5) differs between the different groups. Technicians seem to rely most heavily on the extrapolative term and fundamentalists least, whereas intermediates take a position in between. On the other hand forming regressive expectations seems to be most important for fundamentalists, followed by intermediates and least important for technicians. Not surprisingly when we compare the biased coefficients in equation (6) fundamentalists rely significantly too much on the regressive term but not on the extrapolative term. Contrary, technicians orientate on a smaller degree too much on the regressive term, but additionally, they seem to follow too much on trend extrapolation (here the statistical significance is less obvious). Again intermediates find themselves between the other two groups with biased forecasts towards the regressive term. ${ }^{8}$

\subsection{A threshold analysis of expectations}

Following our last results we use a switching regression model with different regimes in order to get deeper insights into the structures of US-Dollar/Euro forecast biases. We determine the absolute value of the regressive term as the transition variable $\left(\mathrm{c}_{\mathrm{t}}=\left|\bar{s}_{\mathrm{t}}-s_{\mathrm{t}}\right|\right)$, set the number of regimes to two $(\mathrm{r}=2)$ and choose the threshold level $\left(K^{i}\right)$ via a grid search method (see e.g. Franses and Dijk, 2000, p. 84). Function $\left(\mathrm{I}_{\mathrm{i}}\left[\mathrm{c}_{\mathrm{t}}\right]\right)$ indicates the valid regime in time $t$. The expectations model $\left(\mathrm{f}_{\mathrm{r}, \mathrm{i}}[\bullet]\right)$ shows different parameters, depending on the regime and the group. We follow this approach to see, whether the group specific forecast biases differ between periods, where the US-Dollar/Euro shows large deviations from PPP and periods, where exchange rates are in line with the fundamental concept. Earlier research by Taylor et al. (2001) has in fact indicated that adjustment speed in real exchange rates towards PPP may change faster in periods of large deviations from PPP.

\footnotetext{
${ }^{8}$ To test whether expectation coefficients are statistically different between groups, t-tests are performed. Between fundamentalists and other groups all coefficients are significantly different, whereas this applies between technicians and intermediates only for the regressive term in equation (5).
} 
$\begin{array}{ll}\text { Expectations formation: } & \Delta s_{t+6}^{e, i}=f_{1, i}[\bullet] \cdot I_{i}\left[c_{t}\right]+f_{2, i}[\bullet] \cdot\left(1-I_{i}\left[c_{t}\right]\right) \\ \text { Systematic bias: } & \Delta s_{t+6}^{e, i}-\Delta s_{t+6}=f_{1, i}[\bullet] \cdot I_{i}\left[c_{t}\right]+f_{2, i}[\bullet] \cdot\left(1-I_{i}\left[c_{t}\right]\right)\end{array}$

$$
\begin{aligned}
& \text { with } f_{r, i}[\bullet]=\alpha_{r}^{i}+\gamma_{r}^{i} \cdot\left(s_{t}-s_{t-1}\right)+v_{r}^{i} \cdot\left(\bar{s}_{t}-s_{t}\right) \quad \text { and } r=1,2 \\
& \text { with } c_{t}=\left|\bar{s}_{t}-s_{t}\right| \quad \text { and } I_{i}\left(c_{t}\right)\left\{\begin{array}{l}
=1, \text { if }\left|\bar{s}_{t}-s_{t}\right| \geq \kappa^{i} \\
=0, \text { if }\left|\bar{s}_{t}-s_{t}\right|<\kappa^{i}
\end{array}\right.
\end{aligned}
$$

Table 6 represents the corresponding results and explains our procedure in detail. Summarizing and focusing on the estimation results of equation (7), the group of fundamentalists forms regressive expectations in both regimes, whereas the extent in regime 1 is greater (periods of major exchange rate deviations from PPP). This could contribute to stabilization in exchange rates and the utility of PPP. Additionally fundamentalists rely on trend extrapolation, but only in regime 2 (periods of minor exchange rate deviations from PPP). Contrary, technicians show a mix of regressive and extrapolative formation in both regimes. Further and looking at the parameter estimations of equation (8), all groups show a regressive bias in regime 1 but not in regime $2 .{ }^{9}$ Finally we reveal also an extrapolative bias in the expectation formation of technicians but only for regime 1 , while fundamentalists still do not show any adherence on an extrapolative bias. These results on forecasting bias may cause some worries: they indicate that expectations about mean reversion in exchange rates towards PPP might appear too optimistic; moreover, some professionals - the technicians - seem to form even extrapolative expectations to an unjustified degree and might consequently destabilize the market.

\subsection{Performance of expectations}

Our last analyses examine the forecast ability of the separated groups. Additionally we deal with related forward rates and random walk forecasts. The results are shown in Table 7 and include four accuracy tests applied to corresponding point forecasts and a hit rate (share of right direction forecasts) applied to underlying trend forecasts.

To cut a story short, one can not detect significant differences in the performance between fundamentalists, intermediates and technicians. However, if we con-

\footnotetext{
${ }^{9}$ The different behavior of the bias depending on the currently valid regime approves, that in conventional regressions the bias varies over time (see, Frankel and Froot, 1987a, p. 150).
} 
centrate on the analysis for point forecasts such as MAE (mean absolute error) and RMSE (root mean square error), the random walk beats all groups of forecaster as well as the forward rate, even though the latter one performs also better than the forecaster groups. On the other hand if we consider the hit rate, which is calculated upon underlying trend forecasts, that all groups perform significantly better than the random walk, whereas forecasts based on the forward rate are significantly worse than the random walk. ${ }^{10}$ In addition to that, corresponding differences between the forecaster groups and the forward rate are highly significant. ${ }^{11}$

Taken together, both groups, fundamentalists and technicians, perform upon point forecast measures significantly worse than the random walk, as well as the forward rate. On the other hand, if we consider just the implicit trend forecasts, than these forecaster groups outperform the other forecast series. It definitely shows that participants of the ZEW survey have forecasting abilities despite all kinds of biases revealed (see also Wakita, 1989). If they would be able to avoid systematic distortions there would be an even better chance to forecast. This result stands in line with Elliott and Ito (1999, p. 455), "that more is going on in the models of the respondents than static expectations with random noise".

\section{Conclusions}

Our study on exchange rate expectations intends to bring fresh evidence into an established field. Thus, we first reproduce the stylized fact of non-rational expectation formation and conclude that our participants do not differ in this respect from those of earlier survey studies. We also notice - largely in line with the literature - that forecasts are biased, in particular that the sign of the bias does change over time. Our objective is, however, not just to perform the conventional tests for another survey at another time. We rather aim for adding a completely different and most interesting kind of information to the field in order to understand biased forecasts better: our survey is the first to combine a large data set of forecasts with information on the forecasters' preferred analytical instrument, e.g. their reliance on fundamental analysis.

\footnotetext{
${ }^{10}$ Note that the origin of the individual forecasts is of qualitative nature. Derived point forecasts are only used for comparative purposes.

${ }^{11}$ Performance statistics separated by PPP regimes show, that the groups perform better in regime 2. Moreover, if we pull up the hit rate, their out performance to the forward rate will get even bigger.
} 
We reveal that the preference of fundamental analysis is useful information to understand the way how exchange rate expectations are formed. Moreover, we detect that the preference of fundamental analysis helps to understand specific biases: fundamentalists believe too much in mean reversion of the US-Dollar/Euro, more than other participants. So, this misguided belief is consistent with poor forecasting performance. However, any claim of superior performance due to reliance on technical analysis is premature. Although the technicians' expectations are less distorted by too much reliance on PPP, they also show a misguided belief: they extrapolate shortterm trends as one would assume, yet, they extrapolate too much. Consequently, this additional expectation distortion hinders them to form appropriate forecasts.

Overall, we argue that our data provide new evidence on possible sources of systematic forecasting biases. In addition to Ito's (1990) discovery of wishful thinking we reveal too much belief in mean reversion which can be interpreted usefully as too much belief in PPP. One ought to speculate whether Ito's and our detections may be connected to behavioural distortion in decision making: in this sense, our participants possibly overestimate the precision of their knowledge of exchange rate changes relying too much on their interpretation of PPP. However, there is also a competing explanation for fully rational forecasters, who show proper understanding of fundamentals: as we are covering professionals with somewhat long-term orientation, markets might act inconsistent to them. Then, foreign exchange markets are possibly dominated by short-term considerations which are less consistent with the directions that fundamentals advise.

\section{Acknowledgement}

For helpful comments we would like to thank Michael Frömmel.

\section{References}

Bénassy-Quéré, Agnès, Sophie Larribeau and Ronald MacDonald (2003), Models of Exchange Rate Expectations: How Much Heterogeneity? Journal of International Financial Markets, Institutions and Money, 13, 113-136.

Cavaglia, Stefano, Willem F.C. Verschoor and Christian C.P. Wolff (1993), Further Evidence on Exchange Rate Expectations, Journal of International Money and Finance, 12, 78-98. 
Carlson, John A. and Michael Parkin (1975), Inflation Expectations, Economica, 42, 123-138.

Diebold, Francis X. and Jose A. Lopez (1996), Forecast Evaluation and Combination, in: G. S. Maddala and C. R. Rao (eds.), Handbook of Statistics, 14, Amsterdam, 241-268.

Dominguez, Kathryn M. (1986), Are Foreign Exchange Forecasts Rational? New Evidence from Survey Data, Economics Letters, 21, 277-281.

Elliott, Graham and Takatoshi Ito (1999), Heterogeneous Expectations and Tests of Efficiency in the Yen/Dollar Forward Exchange Rate Market, Journal of Monetary Economics, 43, 435-456

Frankel, Jeffrey A. and Kenneth A. Froot (1987a), Using Survey Data to Test Standard Propositions Regarding Exchange Rate Expectations, American Economic Review, 77:1, 133-153.

Frankel, Jeffrey A. and Kenneth A. Froot (1987b), Short-Term and Long-Term Expectations of the Yen/Dollar Exchange Rate: Evidence from Survey Data, Journal of the Japanese and International Economies, 1, 249-274.

Frankel, Jeffrey A. and Kenneth A. Froot (1990), Chartists, Fundamentalists, and Trading in the Foreign Exchange Market, American Economic Review, 80:2, 181-185.

Frankel, Jeffrey A. and Andrew K. Rose (1995), Empirical Research on Nominal Exchange Rates, in: G. Grossmann and K. Rogoff (eds.), Handbook of International Economics, Vol. III (Amsterdam et al.: North-Holland), 1689-1729.

Franses, Philip H. and Dick van Dijk (2000), Non-Linear Time Series Models in Empirical Finance, Cambridge et al.: Cambridge University Press, 69-134.

Goodman, Stephen H. (1979), Foreign Exchange Rate Forecasting Techniques: Implications for Business and Policy, Journal of Finance, 34:2, 415-427.

Gehrig, Thomas and Lukas Menkhoff (2005), Extended Evidence on the Use of Technical Analysis in Foreign Exchange, International Journal of Finance and Economics, forthcoming.

Hansen, Lars P. and Robert J. Hodrick (1980), Foreign Exchange Rates as Optimal Predictors of Future Spot Rates: An Econometric Analysis, Journal of Political Economy, 88, 829-853.

Ito, Takatoshi (1990), Foreign Exchange Rate Expectations: Micro Survey Data, American Economic Review, 80:3, 434-449. 
Ito, Takatoshi (1994), Short-Run and Long-Run Expectations of the Yen/Dollar Exchange Rate, Journal of the Japanese and International Economies, 8, 119143.

Kim, Suk-Joong (1997), Testing the Rationality of Exchange Rate and Interest Rate Expectations: An Empirical Study of Australian Survey-Based Expectations, Applied Economics, 29, 1011-1022.

MacDonald, Ronald (2000), Expectations Formation and Risk in Three Financial Markets: Surveying what the Surveys Say, Journal of Economic Surveys, $14: 1,69-100$.

Menkhoff, Lukas and Ulrich Schmidt (2005), The Use of Trading Strategies by Fund Managers: Some First Survey Evidence, Applied Economics, 37, 1719-1730.

Moosa, Imad A. and Abul Shamsuddin (2004), Expectation Formation Mechanisms, Profitability of Foreign Exchange Trading and Exchange Rate Volatility, Applied Economics, 36, 1599-1606.

Newey, Whitney K. and Kenneth D. West (1987), A Simple Positive Semi-Definite Heteroskedasticity and Autocorrelation Consistent Covariance Matrix, Econometrica, 55, 703-708

Rogoff, Kenneth (1996), The Purchasing Parity Puzzle, Journal of Economic Literature, 34, 647-668.

Sarno, Lucio and Mark P. Taylor (2002), The Economics of Exchange Rates, Cambridge et al.: Cambridge University Press.

Stadtmann, Georg (2004), Biases in FX-Forecasts: Evidence from Panel Data, working paper, WHU Koblenz.

Takagi, Shinji (1991), Exchange Rate Expectations: A Survey of Survey Studies, IMF Staff Papers, 1, 156-183.

Taylor, Alan M. and Mark P. Taylor (2004), The Purchasing Power Parity Debate, Journal of Economic Perspectives, 18:4, 135-158.

Taylor, Mark P. (1989), Expectations, Risk and Uncertainty in the Foreign Exchange Market: Some Results Based on Survey Data, The Manchester School, 57, 142-153.

Taylor, Mark P., David Peel and Lucio Sarno (2001), Non-Linear Mean Reversion in Real Exchange Rates: Toward a Solution of the Purchasing Power Parity Puzzles, International Economic Review, 42, 1015-1042. 
Wakita, Shigeru (1989), Are Survey Forecasts Trusted? American Trade Account Deficit and Yen/Dollar Rate, Economics Letters, 29:4, 339-344.

ZEW Centre for European Economic Research (2004), Financial Market Report, 13:2. 
FIGURE 1 US-Dollar/Euro realizations, PPP exchange rates and consensus forecasts

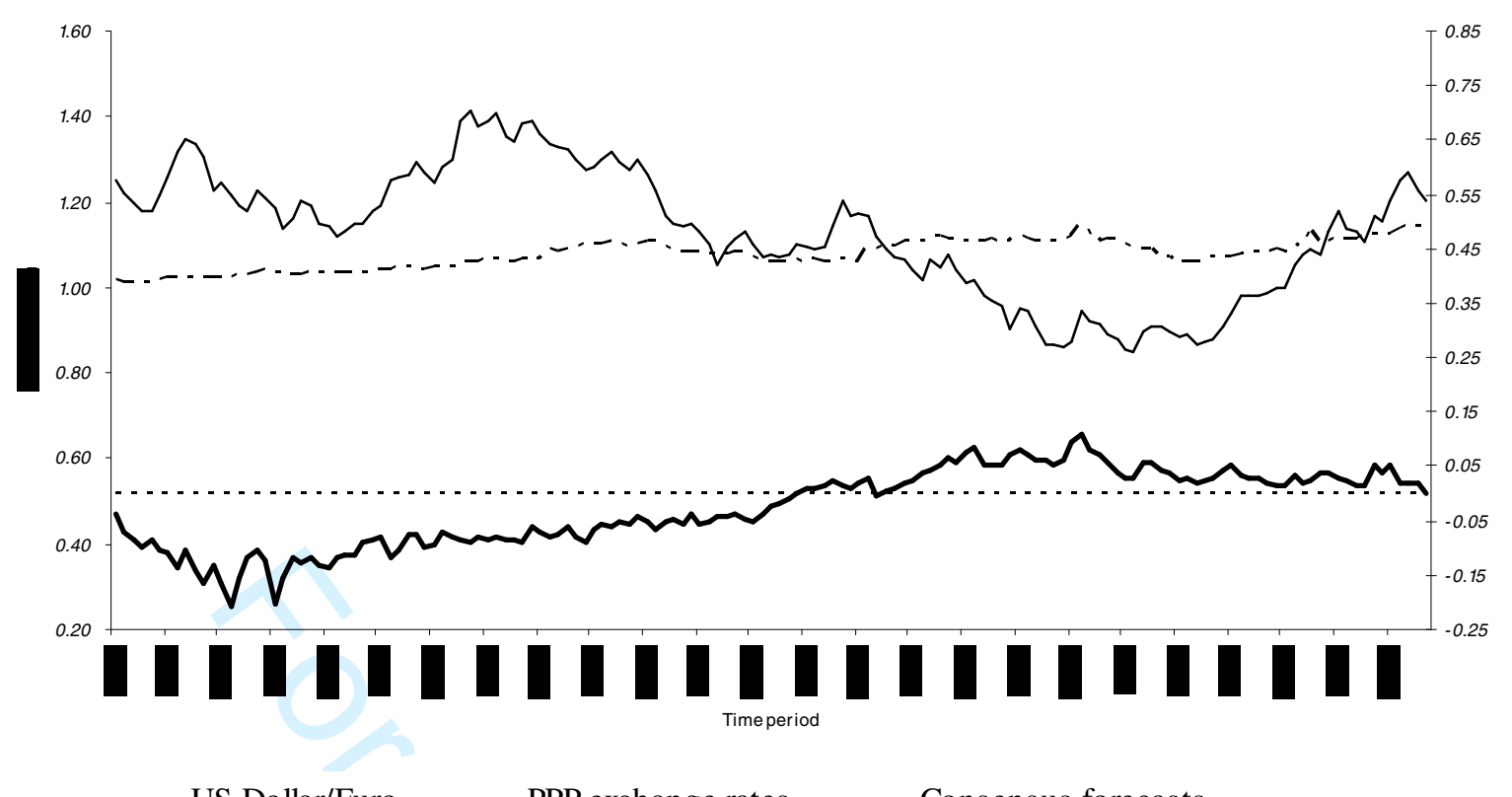

Note:

This figure shows actual realizations of the US-Dollar/Euro and US-Dollar/Deutsche Mark exchange rates, where the latter are transformed on the official exchange rate between the Deutsche Mark/Euro of 1.95583 (left scaled). In addition to that it shows PPP exchange rates, which are calculated upon the PPP concept (left scaled) and consensus change predictions (right scaled). The consensus data were generated with the quantification method introduced by Carlson and Parkin, 1975 (for further details see note in Table 1). To calculate the fundamental exchange rates we used the PPP concept (further explanations are given in chapter regressive expectations). Whereas the US-Dollar/Euro as well as the PPP exchange rates are presented in their levels (corresponding left axis), the consensus data are shown in their changes (corresponding right axis). It can be seen, that the swap of the consensus forecasts from an appreciation of the US-Dollar/Euro to a depreciation occurred around the same time, when the US-Dollar/Euro crossed the line of the PPP exchange rates. Furthermore the amplitudes show a similar pattern, at least in their peaks. 
TABLE 1. Statistics of consensus forecasts, forward rates and exchange rates

\begin{tabular}{|c|c|c|c|c|c|c|}
\hline & \multicolumn{2}{|c|}{ Consensus forecasts } & \multicolumn{2}{|c|}{ Forward rates } & \multicolumn{2}{|c|}{ Exchange rates } \\
\hline & $S_{t+6}^{e}$ & $\Delta s_{t+6}^{e}$ & $S_{t+6}^{f}$ & $\Delta s_{t+6}^{f}$ & $S_{t+6}$ & $\Delta s_{t+6}$ \\
\hline Mean & 1.1169 & -0.0141 & 1.1297 & 0.0006 & 1.1294 & 0.0033 \\
\hline Variance & 0.0120 & 0.0037 & 0.0224 & 0.0006 & 0.0221 & 0.0052 \\
\hline SD & 0.1094 & 0.0604 & 0.1497 & 0.0249 & 0.1487 & 0.0709 \\
\hline Min. & 0.8808 & -0.1470 & 0.8464 & -0.0604 & 0.8510 & -0.1304 \\
\hline Max. & 1.3282 & 0.1312 & 1.4358 & 0.0292 & 1.4120 & 0.1828 \\
\hline
\end{tabular}

Note:

Using the method of Carlson and Parkin (1975) to derive aggregate point expectations requires two assumptions. First, each individual forecast is based upon a subjective probability distribution concerning the outcome of this forecast. However, applying the logistic distribution did not yield the results in any qualitatively different way. Second, the corresponding means of the individual probability distributions follow-up a normal distribution, which can be justified with the Central Limit Theorem. Furthermore we have to set a scaling factor, which displays the threshold, of which the forecasters perceive noticeable changes in the exchange rate. We choose a symmetric scaling factor of three percent. In a special survey the participants of the ZEW Financial Market Survey were asked to reveal their individual thresholds in correspondence to their different forecasts. The average median for the USDollar/Deutsche Mark was a symmetric threshold of roughly three percent. Nevertheless, choosing other thresholds around three percent, didn't show any qualitatively different results. Taylor (1989) also uses the normal distribution and sets his scaling factor on 2.5 per cent. Other methods like choosing the threshold that the mean expected change is equal to the mean actual change or that squared prediction errors are minimized seem inappropriate because of overwhelming evidence towards irrational and inaccurate exchange rate expectations. Finally, in order to rescue some data points, in cases where the probability of a category is zero, we used neighboring estimated volatilities to compute the forecast (Carlson and Parkin, 1975, p. 130-131).

$\mathrm{S}^{\mathrm{e}}$ is defined as the (consensus) forecast of the US-Dollar/ Euro, whereas $\Delta \mathrm{s}^{\mathrm{e}}$ represents the percentage change forecast of the US-Dollar/ Euro.

$S^{f}$ is defined as the implicit forecast of the US-Dollar/ Euro based upon the 6 month LIBOR rate difference and $\Delta s{ }^{f}$ represents the corresponding change forecast in percentage.

$S \quad$ is defined as the US-Dollar/ Euro and $\Delta \mathrm{s}_{\mathrm{t}+6}$ represents the percentage change of the USDollar/ Euro from $t$ to $t+6$. 
TABLE 2. Descriptive statistics of the numbers of participants divided by groups

\begin{tabular}{|c|c|c|c|}
\hline \multirow[b]{2}{*}{ Group criteria: } & Fundamentalists & Intermediates & Technicians \\
\hline & & & \\
\hline Fundamental & $X \geq 80$ & $80<X>40$ & $X \leq 40$ \\
\hline Mean & 35 & 80 & 38 \\
\hline Min. & 12 & 9 & 8 \\
\hline Max. & 57 & 122 & 58 \\
\hline $\begin{array}{l}\text { Note: } \\
\text { All measurements } \\
\text { veys from } 12.1991 \\
\text { and "Fundamenta } \\
\text { damental analysis } \\
\text { "Technicians" sho } \\
\text { the participants in } \\
\text { adds up to } 52 \text { per } \\
\text { per cent on flow a } \\
\text { dealing with } 237 \text { in }\end{array}$ & $\begin{array}{l}\text { ased upon a quantity } \\
2004 \text {. Accordingly the } \\
\text { epresents the average } \\
\text { degree of } 80 \text { or mor } \\
\text { and implies the maxi } \\
\text { urvey, whom we categ } \\
\text { considering the mean } \\
\text { s on average (the corr } \\
\text { als as not all participan }\end{array}$ & $\begin{array}{l}\text { The statistics are } \\
35 \text { that correspon } \\
r \text { of people amons } \\
\text { ent. Furthermore } \\
\text { nber of technician } \\
\text { s technicians, the } \\
\text { ole survey is } 30 \text { p } \\
\text { ng overall mean is } \\
\text { ZEW survey resp }\end{array}$ & $\begin{array}{l}\text { d on the ZEW s } \\
\text { ombination "Mea } \\
\text { veys, who use fu } \\
\text { ination "Max." a } \\
\text { survey. Concerni } \\
\text { technical analy } \\
\text { hereas they use } \\
\text { ent). In fact we a } \\
\text { ur questionnaire }\end{array}$ \\
\hline
\end{tabular}

TABLE 3. Testing rational expectations: Unbiasedness and efficiency tests

Test of unbiasedness:

$$
\Delta s_{t+6}=\alpha+\beta \cdot \Delta s_{t+6}^{e}
$$

Test of efficiency:

$$
\Delta s_{t+6}^{e}-\Delta s_{t+6}=\alpha+\beta \cdot F D_{t+6}
$$

\begin{tabular}{lccccccc}
\hline & $\beta$ & $\mathrm{t}: \beta=0$ & $\alpha$ & $\mathrm{t}: \alpha=0$ & $\mathrm{DF}$ & $\operatorname{adj} . \mathrm{R}^{2}$ & $\begin{array}{c}\text { F-test } \\
\alpha=0, \beta=1\end{array}$ \\
\cline { 2 - 8 } & & & & & & & \\
$\Delta s_{t+6}$ & 0.00 & 0.02 & 0.00 & -0.07 & 147 & -0.01 & $19.86^{* * *}$ \\
$\Delta s_{t+6}^{e}-\Delta s_{t+6}$ & $1.79^{* * *}$ & 3.73 & 0.02 & 1.35 & 147 & 0.23 & - \\
\hline
\end{tabular}

Note:

Here, as in the following tables of this paper (except for Table 7), all variables are calculated in natural logarithmic form so that their differences represent corresponding changes:

$\Delta \mathrm{s}_{\mathrm{t}+6} \quad$ is defined as the difference between the current Euro/US-Dollar rate (Deutsche Mark/ US-Dollar-) and their prior six month rate.

$\Delta s^{e} \quad$ is defined as the difference between the expected Euro/US-Dollar consensus rate (Deutsche Mark/US-Dollar-) and their subsequent actual realization.

FD is defined as the forward discount of the Euro/US-Dollar (Deutsche Mark/US-Dollar), calculated upon the difference of 6 month Libor rates.

All regressions are estimated with Newey-West standard-errors (see, Newey and West, 1987). Asterisks refer to the level of significance: *: ten per cent, ${ }^{* *}$ : five per cent, ${ }^{* * *}$ : one per cent. 
TABLE 4. Hybrid model for consensus expectations

Expectations formation:

$$
\Delta s_{t+6}^{e}=\alpha+\gamma \cdot\left(s_{t}-s_{t-1}\right)+v \cdot\left(\bar{s}_{t}-s_{t}\right)
$$

Systematic bias:

$$
\Delta s_{t+6}^{e}-\Delta s_{t+6}=\alpha+\gamma \cdot\left(s_{t}-s_{t-1}\right)+v \cdot\left(\bar{s}_{t}-s_{t}\right)
$$

\begin{tabular}{lccccccc}
\hline & $\gamma$ & $\mathrm{t}: \gamma=0$ & $v$ & $\mathrm{t}: v=0$ & $\alpha$ & $\mathrm{t}: \alpha=0$ & adj. $\mathrm{R}^{2}$ \\
\cline { 2 - 7 }$\Delta s_{t+6}^{e}$ & $0.38^{* * *}$ & 3.81 & $0.35^{* * *}$ & 10.25 & 0.00 & 0.72 & 0.68 \\
$\Delta s_{t+6}^{e}-\Delta s_{t+6}$ & 0.34 & 1.26 & $0.26^{* * *}$ & 2.96 & 0.01 & 0.56 & 0.16 \\
\hline
\end{tabular}

Note:

The extrapolative term represents the previous one month change of the Euro/US-Dollar rate. Longer periods e.g. 3 months or 6 months changes show less significant results therefore we use the one month changes. The equilibrium rate of the foreign exchange rate is based upon the relative PPP concept. Corresponding rates are calculated upon PPI differences between the Euro area and the USA. The use of CPI data could not reveal qualitatively different results. In addition to that robustness checkups show that the parameters indeed vary over time. Specifically we separated by equal time periods, up and down periods of the exchange rate as well as over- and undervaluation periods upon the PPP concept. However, in the majority of cases their signs remain equal.

TABLE 5. Hybrid model for group expectations

$$
\begin{array}{lc}
\text { Expectations formation: } & \Delta s_{t+6}^{e, i}=\alpha+\gamma^{i} \cdot\left(s_{t}-s_{t-1}\right)+v^{i} \cdot\left(\bar{s}_{t}-s_{t}\right) \\
\text { Systematic bias: } & \Delta s_{t+6}^{e, i}-\Delta s_{t+6}=\alpha+\gamma^{i} \cdot\left(s_{t}-s_{t-1}\right)+v^{i} \cdot\left(\bar{s}_{t}-s_{t}\right)
\end{array}
$$

\begin{tabular}{|c|c|c|c|c|c|c|c|c|}
\hline & & $\gamma^{i}$ & $\mathrm{t}: \gamma^{i}=0$ & $v^{i}$ & $\mathrm{t}: v^{i}=0$ & $\alpha^{i}$ & $\mathrm{t}: \alpha^{i}=0$ & $\operatorname{adj.} R^{2}$ \\
\hline Funda- & $\Delta s_{t+6}^{e, 1}$ & 0.14 & 0.58 & $0.46^{* \star \star}$ & 6.18 & 0.00 & -0.54 & 0.59 \\
\hline mentalists & $s_{t+6}^{e, i}-s_{t+6}$ & 0.12 & 0.35 & $0.37^{* \star \star}$ & 3.31 & 0.00 & -0.02 & 0.23 \\
\hline Inter- & $\Delta s_{t+6}^{e, 2}$ & $0.63^{\overline{x \bar{x}}}$ & 2.33 & $0.42^{-\pi \times x}$ & 5.13 & 0.01 & 1.26 & 0.40 \\
\hline mediates & $S_{t+6}^{e, 2}-S_{t+6}$ & 0.58 & 1.54 & $0.33^{* \star *}$ & 3.14 & 0.02 & 1.00 & 0.17 \\
\hline Tech- & $\Delta s_{t+6}^{e, 3}$ & $0.64^{* * * x}$ & 3.32 & $0.40^{z \mp * x}$ & 6.73 & $0.02^{\bar{x}}$ & 2.16 & 0.45 \\
\hline nicians & $s_{t+6}^{e, 3}-s_{t+6}$ & $0.59^{*}$ & 1.79 & $0.31^{* \star *}$ & 3.06 & 0.02 & 1.38 & 0.16 \\
\hline
\end{tabular}

Note:

The extrapolative term as well as the regressive one is calculated in the same way as showed in section 3.2. As well as in above calculations we carried out robustness checks. Eventually the results appeared qualitatively very much alike. It is worth pointing out, that above all the differences between fundamentalists and technicians approved according to corresponding conclusions in this chapter. 
TABLE 6. Hybrid model for group expectations with thresholds

Expectations formation:

$$
\begin{aligned}
& \Delta s_{t+6}^{e, i}=f_{1, i}(\bullet) \cdot I\left[c_{t}^{i}\right]+f_{2, i}(\bullet) \cdot\left(1-I\left[c_{t}^{i}\right]\right) \\
& \Delta s_{t+6}^{e, i}-\Delta s_{t+6}=f_{1, i}(\bullet) \cdot I\left[c_{t}^{i}\right]+f_{2, i}(\bullet) \cdot\left(1-I\left[c_{t}^{i}\right]\right)
\end{aligned}
$$

\begin{tabular}{|c|c|c|c|c|c|c|c|c|c|}
\hline \multirow{5}{*}{$\begin{array}{l}\text { Funda- } \\
\text { mentalists }\end{array}$} & \multirow{3}{*}{$\Delta s_{t+6}^{e, 1}$} & $r$ & $\gamma_{r}^{i}$ & $\mathrm{t}: \gamma_{r}^{i}=0$ & $v_{r}^{i}$ & $\mathrm{t}: v_{r}^{i}=0$ & $\alpha_{r}^{i}$ & $\mathrm{t}: \alpha_{r}^{i}=0$ & $\operatorname{adj.} R^{2}$ \\
\hline & & 1 & 0.06 & 0.16 & $0.46^{* \pi \times}$ & 5.95 & 0.00 & -0.15 & 0.60 \\
\hline & & 2 & $0.29^{* *}$ & 2.22 & $0.37^{* *}$ & 2.45 & -0.01 & -1.12 & 0.32 \\
\hline & & 1 & 0.30 & 0.73 & $0.39^{* * *}$ & 3.42 & 0.00 & -0.16 & 0.30 \\
\hline & & 2 & -0.15 & -0.48 & 0.20 & 0.47 & 0.00 & 0.21 & -0.02 \\
\hline \multirow[b]{2}{*}{ Inter- } & \multirow{2}{*}{$\Delta s_{t+6}^{e, 2}$} & 1 & $0 . \overline{7} 0^{-*}$ & $-\overline{1.7 \overline{5}}$ & $0 . \overline{40^{* *}}$ & 5.01 & $0.03^{-*}$ & $-\overline{1} . \overline{9} \overline{1}$ & $\overline{0.39}$ \\
\hline & & 2 & $0.51^{* *}$ & 2.48 & $0.47^{* \star}$ & 2.29 & -0.01 & -0.72 & 0.31 \\
\hline \multirow[t]{2}{*}{ mediates } & \multirow{2}{*}{$s_{t+6}^{e, 2}-s_{t+6}$} & 1 & $0.92^{* *}$ & 2.03 & $0.33^{* \star *}$ & 3.24 & 0.03 & 1.20 & 0.21 \\
\hline & & 2 & 0.06 & 0.16 & 0.24 & 0.53 & 0.00 & 0.19 & -0.01 \\
\hline \multirow{4}{*}{$\begin{array}{l}\text { Tech- } \\
\text { nicians }\end{array}$} & & 1 & 0.67 & 2.48 & 0.38 & $\overline{6} . \overline{4}$ & $0.03^{-x}$ & $2 . \overline{5} \overline{8}$ & $0 . \overline{3}$ \\
\hline & & 2 & $0.60^{* * *}$ & 3.62 & $0.41^{* * *}$ & 2.71 & 0.00 & -0.01 & 0.40 \\
\hline & \multirow{2}{*}{$s_{t+6}^{e, 3}-s_{t+6}$} & 1 & $0.87^{* *}$ & 2.25 & $0.31^{* \star \star}$ & 3.12 & 0.03 & 1.34 & 0.19 \\
\hline & & 2 & 0.17 & 0.52 & 0.23 & 0.55 & 0.01 & 0.64 & -0.01 \\
\hline
\end{tabular}

$$
\begin{array}{ll}
\text { with } f_{r}(\bullet)=\alpha_{r}^{i}+\gamma_{r}^{i} \cdot\left(s_{t}-s_{t-1}\right)+v_{r}^{i} \cdot\left(\bar{s}_{t}-s_{t}\right) & \text { and } r=1,2 \\
\text { with } c_{t}^{i}=\left|\bar{s}_{t}-s_{t}\right| & \text { and } I\left(c_{t}^{i}\right) \begin{cases}=1 & \text { if }\left|\bar{s}_{t}-s_{t}\right| \geq \kappa^{i} \\
=0 & \text {,if }\left|\bar{s}_{t}-s_{t}\right|<\kappa^{i}\end{cases}
\end{array}
$$

Note:

Regime one represents the periods, when the Euro/US-Dollar deviates ten percent or more from his fundamentally fair value based upon the relative PPP theory. Regime two therefore represents the periods, when the realized exchange rates deviate less than ten percent from PPP exchange rates. The indicator function $\mathrm{I}\left(\mathrm{C}_{\mathrm{t}}\right)$ shows in which regime exchange rates are currently located. Concerning the grid search method, we restrict the search for the threshold in a range of $2.5-25.0$ per cent (with intervals of 2.5 per cent in between). Additionally we require that the number of observations in each of the regimes contains 30 per cent at minimum. Finally, the threshold is selected, if the overall residual sum of squares is minimized. Alternatively, setting wider threshold ranges results in slightly different thresholds between the separated groups; however, the outcomes do not show any qualitative changes. 
TABLE 7. Tests of accuracy and quality of performance

\begin{tabular}{lccccc}
\hline & ME & MAE & RMSE & Theil's U & Hit rate \\
\cline { 2 - 6 } Fundamentalists & -0.0157 & 0.0964 & 0.1226 & 1.5367 & $0.6154^{* * *}$ \\
Intermediates & -0.0319 & 0.0974 & 0.1246 & 1.5613 & $0.5946^{* *}$ \\
Technicians & $-0.0392^{*}$ & 0.0956 & 0.1247 & 1.5681 & $0.5959^{* *}$ \\
Forward rate & -0.0006 & 0.0746 & 0.0912 & 1.1455 & $0.3289^{* * *}$ \\
Random Walk & -0.0010 & 0.0656 & 0.0796 & - & -
\end{tabular}

Note:

Random walk forecasts are calculated on current exchange rates, respectively no change forecast. ME represents the mean error based on Euro/US-Dollar forecasts and realized exchange rates. MAE represents corresponding absolute mean error.

RMSE represents corresponding root mean square error. Differences between groups and other forecast series were examined upon

Theil's $U$ represents the relation between the group specific RMSE and the RMSE of the random walk. Prob. shows the $p$-value for statistical significance.

Hit rate represents the share of right direction forecasts. In brackets you find the p-values of the chi-square test statistic in correspondence to the hypothesis of no directional forecast ability (Diebold and Lopez, 1996, pp. 256-258). Differences between the forecast series were tested upon contingency tables in connection with $\mathrm{X}^{2}$-tests. 